\title{
Assessment of Mechanical Design Parameters for an Aero Gas Turbine Engine Jet Pipe Casing using Finite Element Analysis
}

\author{
Balakumar. C, U. Chandrasekhar, B. Chandra Mohana Reddy
}

\begin{abstract}
Aero Gas Turbine engines power aircrafts for civil transport application as well as for military fighter jets. Jet pipe casing assembly is one of the critical components of such an Aero Gas Turbine engine. The objective of the casing is to carry out the required aerodynamic performance with a simultaneous structural performance. The Jet pipe casing assembly located in the rear end of the engine would, in case of fighter jet, consist of an After Burner also called as reheater which is used for thrust augmentation to meet the critical additional thrust requirement as demanded by the combat environment in the war field. The combustion volume for the After burner operation together with the aerodynamic conditions in terms of pressure, temperature and optimum air velocity is provided by the Jet pipe casing. While meeting the aerodynamic requirements, the casing is also expected to meet the structural requirements. The casing carries a Convergent-Divergent Nozzle in the downstream side (at the rear end) and in the upstream side the casing is attached with a rear mount ring which is an interface between engine and the airframe. The mechanical design parameters involving Strength reserve factors, Fatigue Life, Natural Frequencies along with buckling strength margins are assessed while the Jet pipe casing delivers the aerodynamic outputs during the engine operation. A three dimensional non linear Finite Element analysis of the Jet pipe casing assembly is carried out, considering the up \& down stream aerodynamics together with the mechanical boundary conditions in order to assess the Mechanical design parameters. Keywords: FEM, Jet Pipe Casing, Fatigue, Buckling, Natural Frequency
\end{abstract}

\section{INTRODUCTION}

There has been continued demand worldwide for higher performance lighter fighter aircrafts for various military related missions in defence sector. This has led to development of efficient aero engines capable of providing high thrust / weight ratios [1], low specifics fuel consumption as well as improved component lifing. The overall performance of engine [2] is governed by a wide variety of factors such as individual component efficiency in terms of design, maximum gas temperature, compression ratio and rotational speed, which in turn are bounded by severe material property constraints.

Revised Manuscript Received on June 15, 2020.

*Correspondence Author

Balakumar C*, PhD scholar in, Jawaharlal Nehru Technological University, Anantapur. Email: balakumar@gtre.drdo.in

Dr. U. Chandrasekhar, Program Director, AddWize at Wipro 3D Email: rapidchandra@gmail.com

Dr. Chandra Mohana Reddy, Assistant Professor, HOD, Dept of Mech Engg, JNTUA, Anantapur. Email: cmr_b@yahoo.com

(C) The Authors. Published by Blue Eyes Intelligence Engineering and Sciences Publication (BEIESP). This is an open access article under the CC BY-NC-ND license (http://creativecommons.org/licenses/by-nc-nd/4.0/)
This led to a major shift in current aero engine design and lifing philosophy, especially in military sector - replacing multiple stages of turbine or compressor to a fewer ones but more heavily loaded stages, replacing heavier steels and nickel based super alloys by high strength-low density materials [3-4] such as Titanium alloys in compressor module, replacing solid blades design by more complex hollow ones for achieving higher TET [5] (Turbine Entry Temperature) levels by cooling channels, replacing polycrystalline microstructure to directionally solidified to single crystal for improved high temperature capabilities of materials, thus requiring development of strategic investment casting technologies in place of conventional wrought ones and replacing Safe life [6] based design philosophy to more advanced ones such as fracture mechanics and damage mechanics.

\section{MECHNICAL DESIGN PARAMETERS}

\section{A. Low Cycle Fatigue life}

Fighter jets employ Gas turbines as power plants which are equipped with after burner vis-à-vis reheater for thrust augmentation through final gas expansion in nozzle. The Nozzle is, in turn, structurally and aerodynamically supported by the Jet pipe casing. Aircraft maneuverability depends on the thrust to weight ratio [7] and in order to achieve aero-engine thrust to weight ratio target, weight of each module of the engine must be kept within the target weight. Jet pipe casing with nozzle is one of such components whose weight is optimized by the usage of high strength super alloys and such components are expected to work at maximum material strength limits in order to minimize the material volume and hence weight. Jet pipe assembly is a critical part which is designed for finite life of 0 - Max - 0 Low Cycle Fatigue (LCF) life cycles corresponding to engine start - stop cycles. By carrying out stress analysis corresponding to maximum \& minimum operating condition, cyclic strain range is estimated. While operated at maximum material strength limits, Jetpipe is subject to elasto-plastic condition locally at stress concentrated locations and strain based lifing methodology is used for assessing LCF life cycles. The first LCF lifing methodology involving relationship between stress amplitude and No. of cycles to failure was published by Basquin [8] in 1910. Coffin [9] and Manson [10] published their research work on the estimation LCF life in the years 1954 \& 1953 respectively to bring out the contribution of elastic and plastic strain amplitudes in the assessment of LCF life.

Blue Eyes Intelligence Engineering

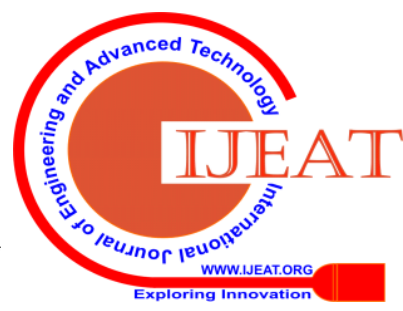




\section{Assessment of Mechanical Design Parameters for an Aero Gas Turbine Engine Jet Pipe Casing using Finite Element Analysis}

Based on the further investigations, Manson along with Gary Halford proposed a method in the form of Universal slope equations [11] for the estimation on Low Cycle Fatigue behaviour of Materials in 1967. This universal slope equation is similar to Coffin - Manson equation in respect of contribution by elastic and plastic strain components.

A typical mission profile of an aircraft is shown in Fig. 1. The profile consists of Taxi-Takeoff-Climb-AccelerateCruise-Descent-Approach-Landing-Taxi in. A fighter aircraft's mission will be consisting of flight maneuvers and mission mix in order to meet the combat situations thereon. This complex mission profile causes a spectrum loading on the critical components of the engine. The strain time history thus developed is fragmented into cycles of different amplitude by means of rain flow counting algorithms [12] as shown in Fig.2. The cycles of different amplitudes are accounted and linear Miner's cumulative damage model is used to assess the damage fraction.

$$
D=\sum \frac{n_{i}}{N_{i}}
$$

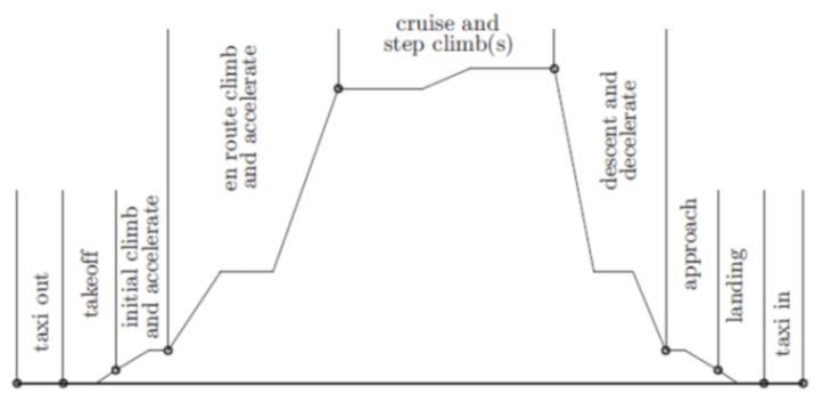

Fig. 1. Mission profile of a typical aircraft

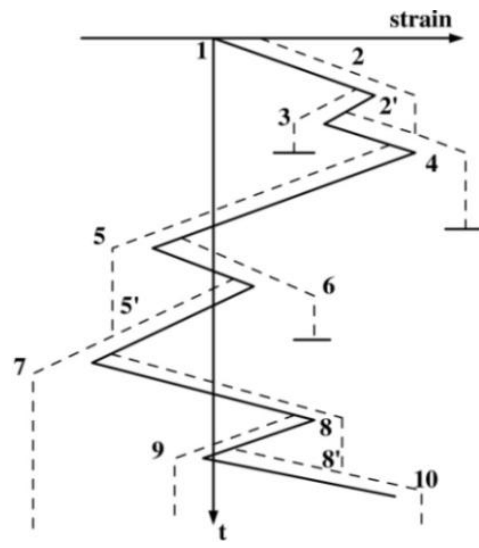

Figure. 2. Rain flow counting

\section{B. Strength Reserve Factors}

During stress analysis gross stress also known as Primary stress [13] is estimated and is used for the assessment of Mechanical Integrity of the Jetpipe assembly through Proof Strength Reserve Factor (PSRF) and Ultimate Strength Reserve Factor (USRF). The secondary stresses and associated strain at notch locations are used to assess LCF life of the component. Secondary stress and corresponding strain are in non-linear relationship unlike the one for primary stress-strain which is linear.

\section{Natural frequencies}

In order to avoid resonance in the entire operation of the flight envelope it is necessary to estimate Natural Frequencies of the Jetpipe. Eigen value modal analysis [14] is carried out to predict natural frequencies and corresponding modes shapes from Eigen values and corresponding Eigen vectors respectively. Simultaneously Vane pass frequency is also estimated to study the possible resonance conditions.

\section{Buckling Strength}

The aero version of the Gas Turbine engine is expected to do maneuver [15] operations in order to meet various combat requirements. Some maneuvers develop forces in such a way that it causes compressive stresses on the Jetpipe. The compressive stress is, in turn, responsible for the buckling [16] of the thin casings. Hence it is necessary to estimate the buckling strength of the casing under such maneuver loads.

\section{CONFIGURATION}

A typical aero gas turbine engine consisting of stages of compressors \& turbines with a combustor in between for energy addition is shown in Fig.3. Afterburner is housed in Jetpipe assembly. As shown in Figure, the assembly is having a circular jet pipe and a nozzle attached at the rear end of the Jet pipe.

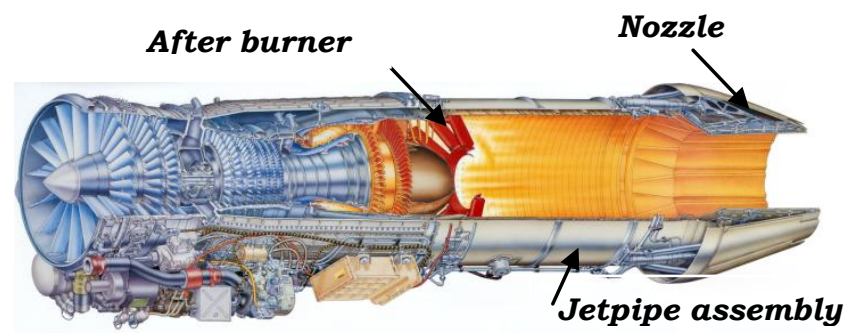

Figure. 3. A typical gas turbine engine

The Jet pipe as shown in Fig.4 is a thin shell like structure attached to engine mount ring on one side. Gas Turbine is a thermodynamic machine runs on Brayton cycle and the thermal efficiency is directly proportional to the maximum temperature in the Thermodynamic cycle. In order to obtain optimum performance with a target efficiency, Nickel based super alloys are used in Gas Turbines. These alloys retain high strength even at elevated temperatures. Such a Nickel based super alloy INCONEL 718 [17] is used for the Jetpipe.

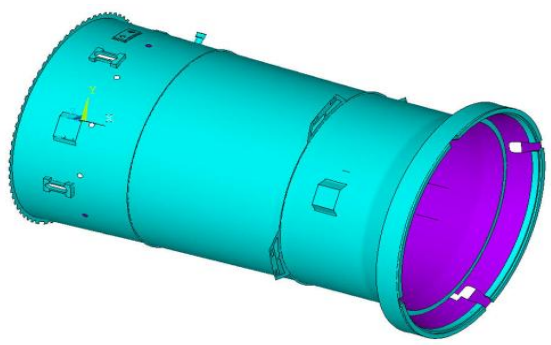

Figure. 4. Configuration of Jet pipe

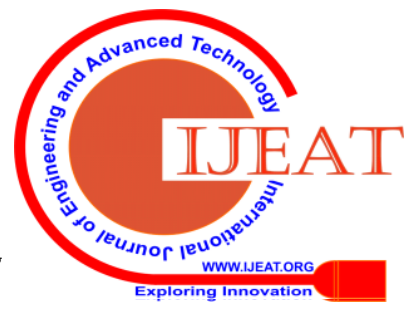




\section{FINITE ELEMENT SIMULATION}

\section{A. Finite Element Model}

Mapped three dimensional Finite Element model was generated using FE software Hypermesh [18]. Linear order shell elements with 6 dof/node were used for the Finite Element model as the casing is a thin shell like member. Element quality parameters [19] like Aspect Ratio, Jacobian, Warp and Skew were maintained and the FE mesh quality was ensured through sanity checking of the FE model. Convergence study was carried out before finalizing the FE model with 64400 elements with 388080 nodal degrees of freedom. The Finite Element model of the casing is shown in Fig.5. When the aircraft accelerates, the lumped mass of Nozzle generates inertial force which causes a tensile loading on the Jet pipe. On the contrary, if the aircraft decelerates, the nature of inertial force is compressive which causes Buckling of the jet pipe.

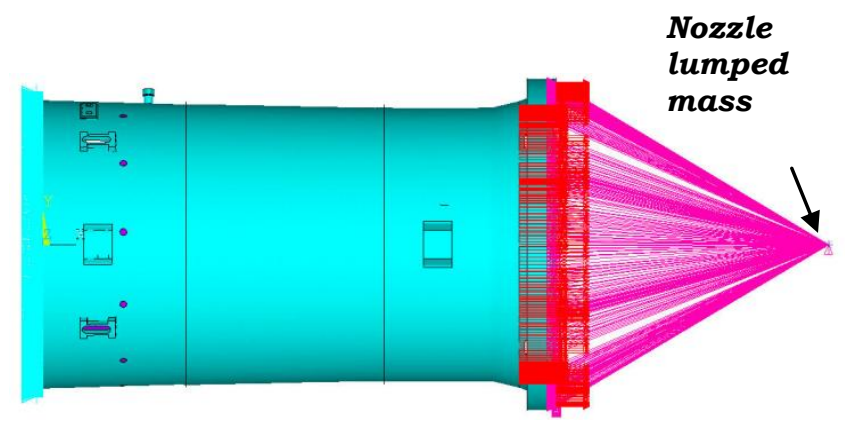

Figure. 5. Finite Element Model with displacement Boundary Conditions

\section{B. Boundary Conditions}

Multipoint Constraints in the form of displacement boundary conditions were applied at the Jet pipe flange to simulate the realistic fixity effect with the adjacent component. Pressure and temperature gradients corresponding to the regular operating conditions were applied along with ' $1 \boldsymbol{g}$ ' for self weight were applied as shown in Fig.6. and Fig.7.

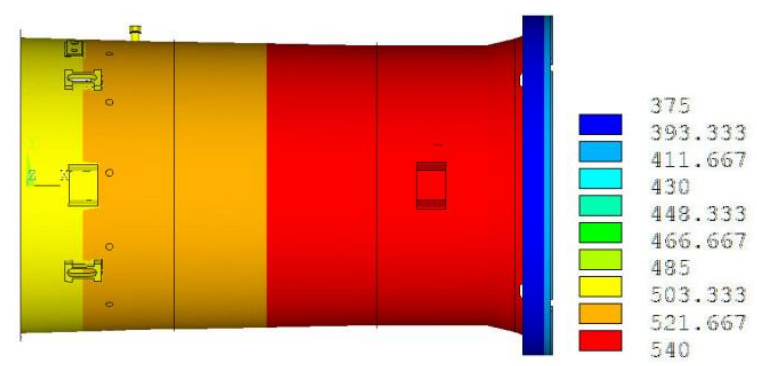

Figure. 6. Temperature distribution in Kelvin

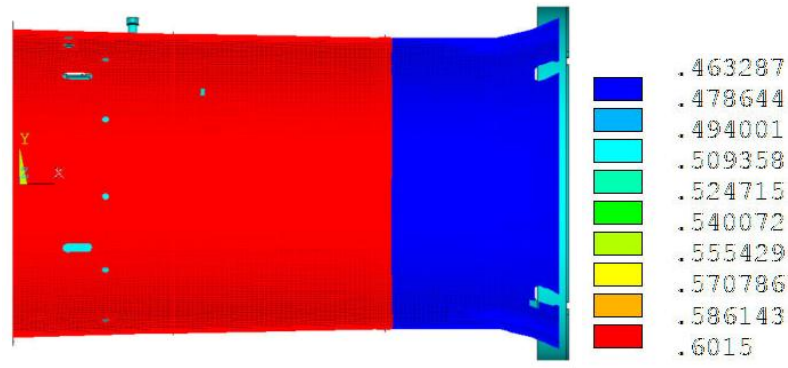

Figure.7. Pressure distribution in MPa

\section{RESULTS AND DISCUSSION}

\section{A. Finite element results:}

Non - Linear Elasto - Plastic analysis was carried out with Displacement and Load boundary conditions using Finite Element software ANSYS[20]. The von Mises stress distribution is as shown in Fig. 8.

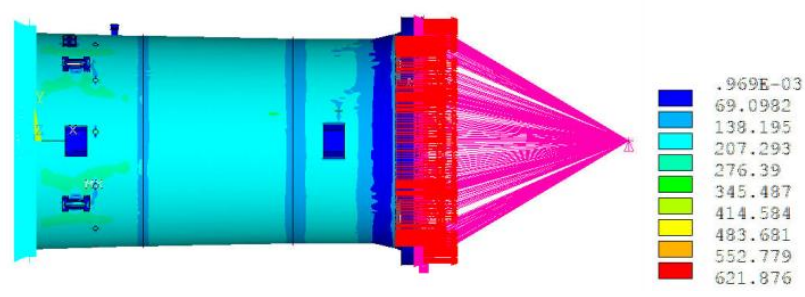

Figure.8. von-Mises stress distribution in MPa

\section{B. Assessment of Strength Reserve Factors:}

While designing any component it is not completely possible to design any component without any notches/stress raisers [21] which do exist in the form of corner edges/variation of cross section and mating contours. The design based on classical approach following the theory of elasticity would consider the concept of Stress Concentration Factor [22] to estimate the rise in stress at the notch locations. Since Finite Element approach is used to predict the stress distribution, the increase in stress at the notches is accurately captured by providing fine mesh at such locations. The convergence study carried out in order to ensure the FE mesh quality provides the assurance that the casing has been meshed with sufficient No. of elements and that the stresses at the notch locations are accurate. Hence it is expected that the stresses at such stress concentrated locations will be more than the allowable yield strength of the material. This localized increase in stress more than the allowable strength does not cause failure which affects the functionality of the Jet pipe casing. Here comes the concept of Proof Strength Reserve Factor (PSRF) and Ultimate Strength Reserve Factor (USRF).

The PSRF is given by the formula

PSRF $=\frac{\text { Allowable Proof Strength }}{\text { Op.Stress } * \text { Safety Margin } * \text { Margin on loads }}-1$

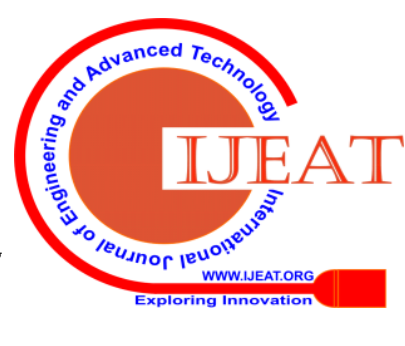




\section{Assessment of Mechanical Design Parameters for an Aero Gas Turbine Engine Jet Pipe Casing using Finite Element Analysis}

The USRF is given by the formula

$U S R F=\frac{\text { Allowable Ultimate Strength }}{\text { Op.Stress } * \text { Safety Margin } * \text { Margin on loads }}-1$

If the formula is grossly observed, it would reveal that it is as good as FOS = Strength/Stress. Here the allowable strength is reduced by Margin of safety (1.25) \& Margin for other loads (1.05). The value of gross stress in the casing is considered as the operating stress which is less than the yield strength as it is seen in Fig. 6. With deduction of 1 , if $\operatorname{PSRF}=0$, it is just meeting the requirement and there is no reserve factor in the strength. Hence the acceptance criteria for the PSRF \& USRF are

$$
P S R F>0 \text { and } U S R F>0
$$

From the experience gained in the full scale component testing and analysis, the PSRF $=0.1$ or more is desirable. Proof Strength Reserve Factor (PSRF) and Ultimate Strength Reserve Factor (USRF) are estimated for the casing to be $\mathbf{1 . 3 5}$ and $\mathbf{2 . 2 9}$ respectively.

\section{Assessment of Low Cycle Fatigue Life:}

Strain based life prediction approach is used for the assessment of LCF life of the components which are subject to Engine Start-Stop cycles. Manson \& Gary Halford Universal slope equations [11] are used for the estimation of LCF life. This equation caters for both Elastic and Plastic strains.

$$
\begin{gathered}
\varepsilon_{\text {total }}=\varepsilon_{\text {elastic }}+\varepsilon_{\text {plastic }} \\
\varepsilon_{\text {total }}=\frac{3.5 *\left(\text { UTS }-\sigma_{\text {mean }}\right)}{E} N_{f}^{-0.12}+D^{0.6} * N_{f}^{-0.6}
\end{gathered}
$$

where $\varepsilon_{\text {total }}, \varepsilon_{\text {elastic }}$ and $\varepsilon_{\text {plastic }}$ are total, elastic and plastic strains respectively

$N_{f}=$ Number of Fatigue cycles

UTS = Ultimate Tensile Strength

$\mathrm{E}=$ Elastic Modulus

$\mathrm{D}=$ Fracture Ductility = -ln(1-\%RA)

$\sigma_{\text {mean }}=$ Mean stress $=$ von Mises stress $/ 2$

(if Stress ratio $\mathrm{R}=0$ )

$\mathrm{RA}=\%$ Reduction in area

Data for life estimation:

$\varepsilon_{\text {total }}=0.00408$

$\mathrm{R}=0$ (Stress Ratio)

von_Mises $=893 \mathrm{MPa}$ [2]

$\mathrm{E}=190572 \mathrm{MPa}$

$\mathrm{UTS}=1000 \mathrm{MPa}$

$\mathrm{RA}=20 \%$ Reduction in area

Solving the Non - Linear equation (4) using the data, the LCF of the Jet pipe is assessed to be 21792 cycles.

\section{Estimation of Natural frequencies:}

Aerodynamic excitations caused by engine flow path pressure perturbations are the sources of the excitation for the engine structure in flow path to vibrate. This vibration may lead to High Cycle Fatigue failure [23]. Since Jetpipe is located in the rear end of the engine and in the gas flow path, the natural frequencies of the casing need to be estimated in order to assess the structural integrity from the resonance point of view. The stream of hot gases expanded through the turbines is encountering a flow path liner before entering the Jet pipe casing and the nozzle. The stream is expected to have many harmonics with vane pass frequency [24] as a predominant one.

$$
\text { Vane Pass Frequency }=N_{L P T} * N_{G V}
$$

where

$\mathrm{N}_{\mathrm{LPT}}=183.33 \mathrm{~Hz}$

$\mathrm{N}_{\mathrm{GV}}=9$

The vane pass frequency $=1650 \mathrm{~Hz}$

Eigen value Finite Element Modal analysis was carried out and first twenty frequencies were estimated. Eigen value problem for modal analysis involves stiffness and mass matrices with applied load to be zero.

$$
M \ddot{x}+K x=0
$$

First two frequencies with mode shapes are plotted here in Figure .9 to Figure 10. All the 20 frequencies are less than the Vane Pass Frequency and hence the Jet pipe assembly is not likely to encounter any resonance during the entire operation envelop.

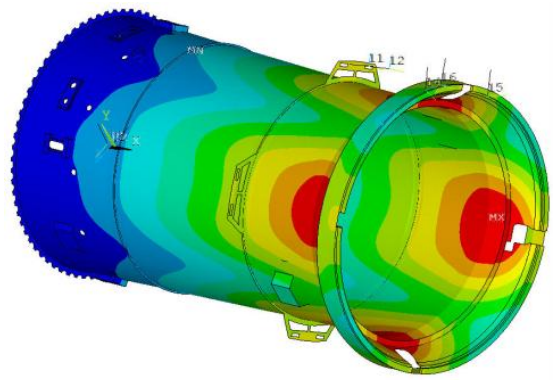

Figure.9. First Mode shape, $79.23 \mathrm{~Hz}$

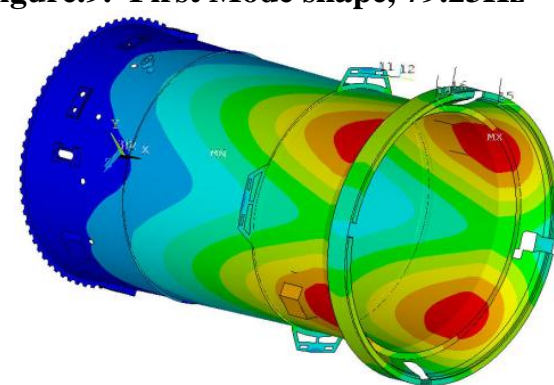

Figure.10. Second Mode shape, $80.48 \mathrm{~Hz}$

\section{E. Buckling Strength estimation:}

The aero version of the Gas Turbine engine is expected to do maneuver operations in order to meet various combat requirements. Some maneuvers develop forces in such a way that it causes compressive stresses on the casing. The compressive stress is, in turn, responsible for the buckling of the thin casings. Hence it is necessary to estimate the buckling strength of the casing under such maneuver loads. Bifurcation buckling occurs when a member or structure converts membrane strain energy into bending strain energy with no change in externally applied load.

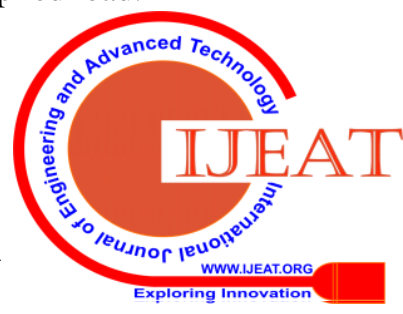


Bifurcation buckling is an Eigen value problem, similar to vibration problems, but with mass matrix [M] replaced by stress stiffness matrix $[\mathrm{K} \sigma]$ which accounts for the membrane stresses on lateral deflection. This is similar to Eigen Value problem where Eigen values yield Buckling factors and the Eigen vectors giving the buckling mode shapes. Bifurcation buckling analysis [25] was carried out and the structural requirement is that the first Buckling factor should be more than or equal to 1.5 as shown in Figure. 11.

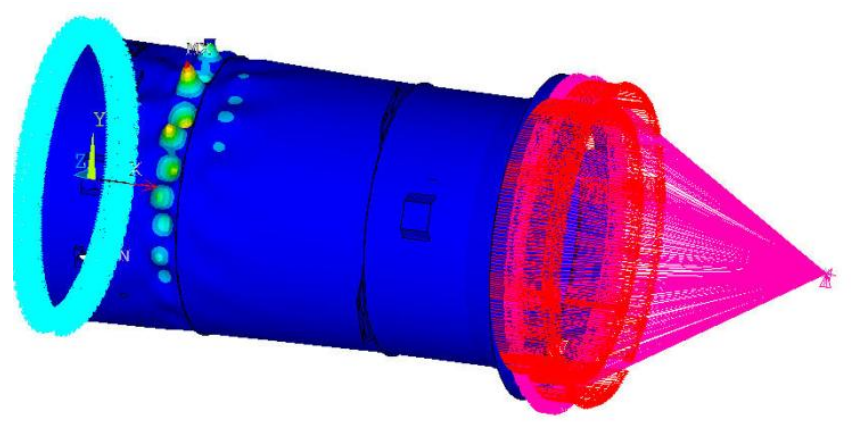

Figure.11. First Buckling Mode shape, $\mathrm{BF}=1.62$

\section{CONCLUSION}

The mechanical design parameters pertaining to Jetpipe assembly were identified based on the primary failure modes were studied. Based on the finite element analysis of the Jetpipe for Aerodynamic pressure \& temperature with boundary conditions, the Mechanical design parameters were estimated. Apart from meeting the Aerodynamic performance requirements, the Jetpipe assembly is also meeting all the structural requirements in terms of Strength Reserve Factors, Fatigue Life, Natural Frequencies and Buckling strength.

\section{ACKNOWLEDGEMENTS}

The authors express their gratitude to the Director, Gas Turbine Research Establishment, Bangalore for permitting to publish this work. The authors are thankful to Shri. Nazar. P, Group Director and Shri. BVA Patnaik, Technical Director for their support and encouragement.

\section{REFERENCES:}

1. J. D. Mattingly., H. H. William, T. P. David, Aircraft Engine Design, AIAA publication Series, 2002

2. H. Cohen, G. F. C. Rogers, H. I. H. Saravanmuttoo, 'Gas Turbine Thory' Prentice Hall

3. Sailendra Kumar Bohidar, Ravi Dewangan, Prof, Kalpit Kaurase,' Advanced materials used for different components of Gas Turbine', International Journal of Scientific Research and Management', Volume-1, Issue-7, Oct 2013.

4. J Hannis, G Mc Colvin, C J Small, J Wells, Draft of comment, Mat UK Energy Materials Review, Material R \& D priorities for Gas Turbines based power generation, July 2007.

5. Robert W. Koenig \& Gerald A. Kraft,' Influence of High turbine inlet temperature engines in a methane fueled SST when takeoff jet noise limits are considered' NASA Technical Note TN D-4965.

6. G. Asquith \& A. C. Pickard, " Fatigue testing of gas turbine components', Full scale fatigue testing of components and structures' edited by K. J. Marsh, Butterworth publishers, 1988.

7. Philip P. Walsh and Paul Fletcher,' Gas Turbine performance', $2^{\text {nd }}$ edition, Blackwell publishing company, 2004.

8. Basquin, O. H, The Exponential law of endurance tests', Proceedings, American Society for Testing and Materials, ASTEA, Vol, 10, 1910.

Published By:

Blue Eyes Intelligence Engineering and Sciences Publication
9. Coffin Jr, L. F, A study of the effects of cyclic thermal stresses on a Ductile metal' TRANS. ASME, Vol, 76, 1954.

10. Mansos. S. S, 'Behaviour of Materials under conditions of thermal stress, Heat transfer Symp, University of Michigan, Engineering Research Instt, 1953.

11. S.S. Manson and Gary Halford, ' A method of estimating High temperature Low Cycle Fatigue behavior of materials', NASA TM X - 52270, Washington, June, 1967.

12. Yi-Wen Cheng \& Jerry J Broz,'Cycle counting methods for fatigue analysis with random oad histories, Institute of Material Science and Engineering, National Bureau of Standards, Colorado, 1986.

13. ASME Boiler and Pressure vessel Code, 1992, Section VIII, Division , American Society of Mechanical Engineers, New York.

14. Klaus-Jurgen Bathe, 'Finite Element Procedures', Prentice Hall, 1996, New Jersey, 07458.

15. Robert. L. Shaw, 'Fighter Combat - Tactics \& Maneuvering' Navel Institute, Annapolis, Maryland, 1987.

16. Robert. D Cooke, David S. Malkus, Michael E. Plesha \& Robert J. Witt, 'Concepts and Applications of Finite Element Analysis', $4^{\text {th }}$ Edition, John Wiley \& Sons (Asia) Pte Ltd.

17. Inco Alloys International, Inc, 4th Edison 1985

18. HYPERMESH, version 10, HTC, Altair, 2008.

19. Nitin S Gokhale, Sanjay S Deshpande, Sanjeev V Badekar \& Anand N Thite, 'Practical Finite Element Analysis', Finite to Infinite, 2008.

20. ANSYS User manual, Release 12.0.1, SAS IP, Inc, 2009.

21. Banantine JA, Comer JJ \& Handrock JL', Fundamentals of Metal Fatigue analyses' Prentice Hall, 1990, New Jersey.

22. Peterson RE, 'Stress Concentration Factors', John Wiley \& Sons, New York, 1974.

23. B. A. Cowles,' High Cycle Fatigue in Aircraft Gas Turbines - an Industry perspective', International Journal of Fracture 80: 147-163, 1996.

24. Fred L. Robinett, Johann F. Gulich \& Thomas Kaiser,' Vane pass vibration- Source assessment and Correction - a practical guide for Centrifugal pumps', Proceedings of the $16^{\text {th }}$ International pump users symposium.

25. C. Balakumar, U. Chandrasekhar \& B. Chandra Mohana Reddy, Bifurcation Buckling Of A Corrugated Jet Pipe Liner For An AeroEngine Afterburner' International Journal of Engineering Science and Technology', Vol 9, No.11, Nov 2017.

\section{AUTHORS PROFILE}

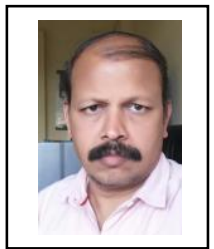

Balakumar C, PhD scholar in Jawaharlal Nehru Technological University, Anantapur. Scientist in Gas Turbine Research Establishment

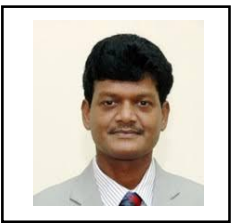

Dr. U. Chandrasekhar, Program Director, AddWize at Wipro 3D, Former Pro Vice Chancellor, Vel Tech Dr.RR \& Dr.SR Technical University Former Scientist and Additional Director, Gas Turbine Research Establishment

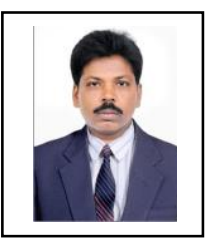

Dr. Chandra Mohana Reddy, Assistant Professor, Head of the Department, Department of Mechanical Engineering Chancellor, Jawaharlal Nehru Technological University, Anantapur 